\title{
Galvanically induced potentials to enable minimal tribochemical wear of stainless steel lubricated with sodium chloride and ionic liquid aqueous solution
}

\author{
Tobias AMANN ${ }^{1, *}$, Felix GATTI ${ }^{1,2}$, Natalie OBERLE ${ }^{1}$, Andreas KAILER ${ }^{1}$, Jürgen RÜHE ${ }^{3}$ \\ ${ }^{1}$ Fraunhofer Institute for Mechanics of Materials IWM, Woehlerstr. 11, Freiburg 79108, Germany \\ ${ }^{2}$ Institute for Macromolecular Chemistry, University of Freiburg, Freiburg 79104, Germany \\ ${ }^{3}$ IMTEK - Department of Microsystems Engineering, University of Freiburg, Georges-Koehler-Allee 103, Freiburg 79110, Germany \\ Received: 07 July 2017 / Revised: 30 October 2017 / Accepted: 17 November 2017 \\ C The author(s) 2017. This article is published with open access at Springerlink.com
}

\begin{abstract}
The effect of galvanically induced potentials on the friction and wear behavior of a 1RK91 stainless steel regarding to tribocorrosion was investigated using an oscillating ball-on-disk tribometer equipped with an electrochemical cell. The aim of this investigation is to develop a water-based lubricant. Therefore 1 molar sodium chloride $(\mathrm{NaCl})$ and $1 \%$ 1-ethyl-3-methylimidazolium chloride $\left[\mathrm{C}_{2} \mathrm{mim}\right][\mathrm{Cl}]$ water solutions were used. Tribological performance at two galvanically induced potentials was compared with the non-polarized state: cathodic potential-coupling with pure aluminum- and anodic potential-coupling with pure copper. Frictional and electrochemical response was recorded during the tests. In addition, wear morphology and chemical composition of the steel were analyzed using scanning electron microscopy (SEM) and X-ray photoelectron spectroscopy (XPS), respectively.

The galvanically induced cathodic polarization of the stainless steel surface results in electrochemical corrosion protection and the formation of a tribolayer. Cations from the electrolyte (sodium $\mathrm{Na}^{+}$and 1-ethyl3-methylimidazolium $\left[\mathrm{C}_{2} \mathrm{mim}\right]^{+}$) interact and adhere on the surface. These chemical interactions lead to considerably reduced wear using $1 \mathrm{NaCl}(86 \%)$ and $1 \%$ 1-ethyl-3-methylimidazolium chloride $\left[\mathrm{C}_{2} \mathrm{mim}\right][\mathrm{Cl}](74 \%)$ compared to the nonpolarized system. In addition, mechanical and corrosive part of wear was identified using this electrochemical technique. Therefore this method describes a promising method to develop water-based lubricants for technical applications.
\end{abstract}

Keywords: sliding wear; tribochemistry; potential controlled friction and wear; galvanic coupling; ionic liquids; tribolayer formation

\section{Introduction}

Friction and wear occurs in mechanically driven technical systems and causes enormous economic costs, which are estimated up to $\approx 6 \%$ U.S. gross national product [1]. In combination with the possibility to diminish the environmental impact of tribological applications, it is inevitable to increase the energy efficiency and durability of their components in sliding or rolling contacts [2-4]. These challenges have been identified and are reflected in current research, which focusses increasingly on energy efficiency, sustainability and "green" tribology [5]. Therefore current research topics in the field of tribology consist in the development of water-based lubrication [6] and the reduction of friction losses to increase the energy efficiency of technical systems [7]. However, there is a common disregard of tribochemical effects in friction

* Corresponding author: Tobias AMANN, E-mail: tobias.amann@iwm.fraunhofer.de 
and wear, though especially rolling and sliding bearings in machines and systems that are exposed to environmental influences or only lubricated by surrounding media (e.g., pumps) are subjected to increased corrosive wear. For engineering materials it is a common scenario to be exposed simultaneously to mechanical damage and electrochemical corrosion [8]. Under these conditions complex tribochemical reactions and surface interactions take place, which lead to corrosive wear [9]. As a consequence, the sliding surfaces of bearings and mechanical seals may be severely damaged after only a short period of use [10]. For the affected technical equipment, devices, and machines there is a need to reduce the damage caused by tribochemical reactions to increase the service life and durability.

To prevent tribocorrosion, corrosion resistant materials, coatings, or lubricants are used. Since 2001 ionic liquids (ILs) have been identified as novel substances with promising tribological properties as lubricants [11-13] and as additives [14-18]. In addition, it has been reported that ILs can be used at electrified interfaces to improve friction and wear $[19,20]$. Li et al. have recently shown that ionic liquids even form solvation layers on surfaces that are strongly influenced by electric potentials and may effectively prevent solid-solid contact in nanotribological contacts enable extremely low friction coefficients [20]. But also other surfactant containing aqueous solutions can be used to actively influence friction and wear by the application of electrochemical potentials [21-24]. These investigations were conducted using an external voltage generator. This experimental approach has been frequently published and is called potential controlled friction (PCF) $[25,26]$. The relevant surface mechanisms that influence the tribochemical behavior are variation of electric double layers [27] electro-kinetic effects, chemisorption, and physisorption of surfactants and chemical reactions [28].

Fundamental investigations on the nanoscale revealed that dynamic superlubricity can be realized accompanied by the elimination of wear [29]. Atomic force microscopy (AFM) studies using surfactant micelles between silica surfaces showed liquid superlubricity [30]. Realizing this state of vanishing friction and wear on the macroscale would come along with high energy savings and increased lifetime of technical applications. Due to these findings bridging the gap between concepts of superlubricity, wearless sliding, and friction control on the microscopic and macroscopic level are the current challenges in this research field [31]. The hypothesis of this work is based on two tribological mechanisms which arise due to the interaction of ionic molecules on a polarized interface. On the one hand the steel surface is electrochemically protected against corrosion reactions $[32,33]$. On the other hand the polarized surface in combination with ionic molecules can lead to the formation of very stable interfacial layer as it was shown using AFMmeasurements [20]. The molecular orientation of the ILs strongly influence the tribological behavior [34]. Moreover, it was found that $\mathrm{Na}^{+}$ions enhance molecular ordering of water and lead to longer mechanical relaxation times [35]. Even the adhesion and friction characteristics can be controlled using nanoparticulate polymer brushes [36]. Ionic liquids have already been investigated as additives in water lubrication in combination with ceramics [37-40]. Furthermore using a protic ionic liquid ultra-low friction was achieved at the water-lubricated sapphire-stainless steel interface [41]. In addition, it was found that the running-in process reduces with increasing IL/water concentration which is accompanied with more pronounced adhesive and corrosive wear [39]. From a chemical point of view it must be noticed that 1-ethyl-3-methylimidazolium chloride $[\mathrm{C} 2 \mathrm{mim}][\mathrm{Cl}]$ ionic liquid is hydrophilic and can cause decomposition into the $\mathrm{HCl}$ in presence of water and humidity, which has detrimental effect towards metallic tribo-surfaces [11]. As a result, since last five years halogen-free ionic liquids are gaining significant attention [42]. The miscibility of IL with water is strongly affected by the composition of the anion [43]. For example ILs with chloride $[\mathrm{Cl}]^{-}$are complete miscibility with water whereas $\left[\mathrm{PF}_{6}\right]^{-}$containing ILs are almost total immiscible. In addition, the miscibility gets worse with increasing alkyl chain length of the cation. The formation of electric double layers, tribochemical reactions, chemisorption, and interfacial electro-kinetic effects are identified as the most important mechanisms which induce modified friction and wear behavior in electrochemically affected tribological systems and have been discussed elsewhere 
[20, 27, 28, 44, 45]. In the ionic liquid solution, cations adsorb along the surface at negative potentials and arrange into ion/ion pair layers near the interface $[44,45]$. This arrangement is more pronounced at higher polarization [44]. Especially1-ethyl-3-methylimidazolium [ $\left.\mathrm{C}_{2} \mathrm{mim}\right]$ with its rigid and inflexible side chains is able to sternly adsorb with a high packaging density within the interfacial (innermost) layer and the transition zone [25]. But it must be noticed that water can strongly change viscosity, polarity, and surface tension in contrast to the pure IL [46]. Consequently, understanding surface interactions, tribochemistry and electro-chemical phenomena and ordering of molecules on the tribological interface are identified as key factors to realize tribological applications using aqueous lubricants [32]. Both factors, the good miscibility with water and the capability to adsorb with a high packaging density were decisive that 1-ethyl-3methylimidazolium chloride ionic liquid $\left[\mathrm{C}_{2} \mathrm{mim}\right][\mathrm{Cl}]$ was used for this investigation.

The aim of this study is to influence these two mechanisms in macroscopic tribological contacts to control chemical (electrochemical corrosion protection) and mechanical (formation of tribolayer) wear.

Since external electrical supplies are normally too difficult to apply in real technical systems, we did not induce electrochemical potentials externally but simply used galvanic couplings of two suitable materials. In analogy to galvanic corrosion protection techniques using sacrificial anodes, the galvanic coupling relocates electrochemical reactions to the less noble metal surface. This offers the opportunity to protect tribological contacts against accelerated chemical wear [47]. In a chloride environment for example there is a rapid passive film breakdown due to hydrolysis [48, 49]. Recently published own work using ILs [50], aqueous solutions of ILs [51], and sodium chloride [52, 53], we showed how strongly electrochemical potentials, applied in a three-electrode configuration [54], can improve friction, wear, and reduce tribocorrosive reactions. The Effect of potential in tribocorrosion of passive materials such as stainless steel has been previously studied and some degradation mechanisms have been already proposed $[55,56]$. In addition, Vieira et al. found that during rubbing, a galvanic coupling between the worn and unworn area are generated due to the mechanical removal of the passive layer and proposed a galvanic model for describing this effect [57].

The approach of this work is to design a tribosystem, in which tribochemical mechanisms and conditions are most favourable. In this article we show that electrochemical potentials can be generated by combining metals with significantly different corrosion potentials (galvanic coupling) to reach minimal wear in sliding surfaces in aqueous solutions with sodium chloride and an ionic liquid.

\section{Methods and materials}

Friction tests were carried out with a reciprocating ball-on-disk tribometer (diameter ball: $12.7 \mathrm{~mm}$, Co. Optimol Instruments SRV-4) using two different electrolytes (Fig. 1). The test parameters were set to $10 \mathrm{~N}$ normal force, $1 \mathrm{~mm}$ stroke, and $20 \mathrm{~Hz}$ oscillation frequency at room-temperature. Each test was performed three times with test duration of $1.0 \mathrm{~h}$.

A stainless steel disk (Sandvik Bioline 1RK91TM, precipitation hardened, $12 \% \mathrm{Cr}-9 \% \mathrm{Ni}-4 \% \mathrm{Mo}-2 \% \mathrm{Cu}$, ASTM A564, UNS S46910) with a silicon carbide (SiC) ball as counter body were used as tribological test samples. 1RK91 was used because it combines the properties of ordinary austenitic stainless and low alloyed ferritic steels. The arising galvanic potential during the tribological tests, due to different material combination, was measured using a potentiostat with a reference electrode $(\mathrm{Ag} / \mathrm{AgCl})$. To measure the

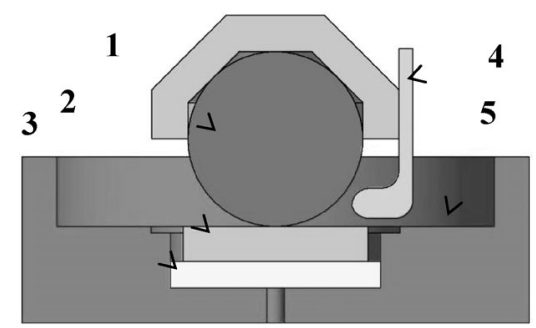

Fig. 1 Sketch of the electrically insulated test setup with ballon-disk geometry. 1. Reciprocating SiC ball; Galvanic cell due to different material combinations: 2. Upper stainless steel disk (1RK91 in contact with $\mathrm{SiC}$ ball); 3. Used materials for lower disk: copper $(\mathrm{Cu})$, aluminium (Al), and teflon (PTFE); 4. Ag/AgClreference electrode to measure the induced electrochemical potential; 5. Electrolyte reservoir filled with lubricant (1 molar sodium chloride $(\mathrm{NaCl})$ and $1 \%$ imidazolium-based ionic liquid $\left.\left[\mathrm{C}_{2} \operatorname{mim}\right][\mathrm{Cl}]\right)$. 
generated galvanic potential the lower disks (galvanic cell) was connected as counter electrode. The contact area with electrolyte was $250 \mathrm{~mm}^{2}$ and with the galvanic coupled metal $240 \mathrm{~mm}^{2}$. To form a galvanic cell pure copper $(\mathrm{Cu})$ as more noble and pure aluminum $(\mathrm{Al})$ as less noble material than 1RK91 was used with a contact area with electrolyte of $210 \mathrm{~mm}^{2}$. Friction tests using PTFE were performed as reference without galvanic coupling due to electric insulation of the material. Surface profiles (Fig. S1 in Electronic Supplementary Material (ESM)), topographies (Fig. S2 in ESM), characteristics (Table S1 in ESM) and chemical composition (Table S2 in ESM) of the used samples are included in the supporting information. As electrolytes aqueous solution (deionized water) of 1 molar sodium chloride $(\mathrm{NaCl})$ and $1 \mathrm{wt} \%$ (1\% by weight) of the imidazolium-based ionic liquid $\left[\mathrm{C}_{2} \mathrm{mim}\right][\mathrm{Cl}]$ (Co. Iolitec, Fig. S3, Table S3) were used. After each friction test the ball and disk were analyzed using color 3D Laser Microscope (VK-9700K, Co. Keyence) to evaluate and quantify wear. Raman microscopy spectra of the wear track to analyze oxidation products were measured using an InVia Renishaw Ramanscope system. The measurements were carried out in air using a He-Ne laser with a wavelength of $532 \mathrm{~nm}$. All spectra were taken three times using a 50× microscope objective, an integration time of $40 \mathrm{~s}$ at a laser intensity of $50 \%$. The spectral window was between 100 and $1,600 \mathrm{~cm}^{-1}$. In addition, scanning electron microscopy (Hitachi S3400N, Type II) and XPS-analysis (X-ray photoelectron spectroscopy, Leybold MAX 100; argon ion sputtering with sputter rate: $2.5 \mathrm{~nm} / \mathrm{min} ; 1 \mathrm{kV} ; 500 \mathrm{nA}$; diameter test point $\sim 200 \mu \mathrm{m}$ ) was used to analyze the wear pattern and the chemical composition of the tribolayer on the 1RK91 material.

\section{Results and discussion}

\subsection{Induced galvanic potential}

Self-corrosion potentials of $\mathrm{Al}(-806 \mathrm{mV}$ vs. $\mathrm{Ag} / \mathrm{AgCl})$ is about $600 \mathrm{mV}$ more negative that of $\mathrm{Cu}(-210 \mathrm{mV}$ vs. $\mathrm{Ag} / \mathrm{AgCl}$ ) as shown in Fig. 2(a). By coupling 1RK91/copper $(\mathrm{Cu})$ and 1RK91/aluminum (Al) nearly the same open circuit potential on the stainless steel is formed as for pure $\mathrm{Al}$ and $\mathrm{Cu}$ (Fig. 2(a)). In a galvanic cell, the base metal is the anode and the
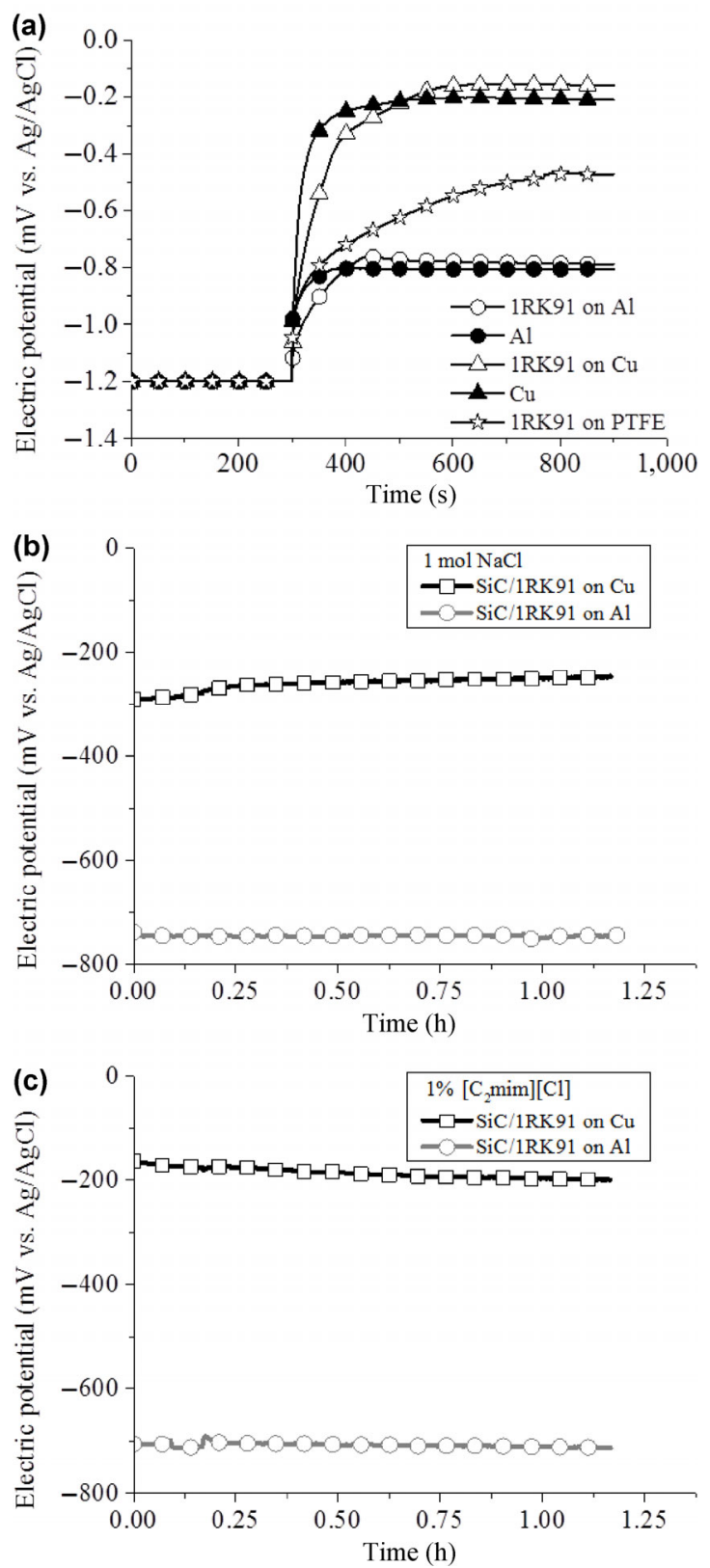

Fig. 2 Electrochemical investigations: (a) Self-corrosion potentials of $\mathrm{Al}$ and $\mathrm{Cu}$ (filled symbols) and open circuit potential using different material combinations in $1 \mathrm{~mol} \mathrm{NaCl}$ solution were steel 1RK91 was set as working electrode (unfilled symbols). Induced galvanic potential during tribological test using 1 molar $\mathrm{NaCl}$ (b) and $1 \%\left[\mathrm{C}_{2} \mathrm{mim}\right][\mathrm{Cl}]$ (c) aqueous solution during tribological test (copper and aluminum contacted as working electrode).

more noble the cathode. This polarization results in an accelerated corrosion of the anode. Due to material combinations different galvanic potentials form: In the material combination 1RK91/Copper $(\mathrm{Cu})$ the stainless steel acts as the anode, whereas in contact with Aluminum (Al) it is set to the cathode. Without 
galvanic coupling an electric potential of $-470 \mathrm{mV}$ vs. $\mathrm{Ag} / \mathrm{AgCl}$ develops and according to the coupling material 1RK91 shows a cathodic ( $\mathrm{Al})$ and anodic $(\mathrm{Cu})$ polarization. Figure 2(b) illustrates the development of the potential during the friction test using 1 molar $\mathrm{NaCl}$ as electrolyte. In contrast to measurement shown in Fig. 2(a) the electric potential was measured using the coupling material $(\mathrm{Al}, \mathrm{Cu})$ as working electrode. The arising potential is quite stable during the whole test with a value of $-250 \mathrm{mV}$ for $1 \mathrm{RK} 91 / \mathrm{Cu}$ and $-750 \mathrm{mV}$ vs. $\mathrm{Ag} / \mathrm{AgCl}$ for 1RK91/Al and shows nearly the same value as shown in Fig. 2(a). Nearly the same values are measured using $1 \%\left[\mathrm{C}_{2} \mathrm{mim}\right][\mathrm{Cl}](1 \mathrm{RK} 91 / \mathrm{Cu}$ : $-200 \mathrm{mV}$ and 1RK91/Al: $-715 \mathrm{mV}$ vs. Ag/AgCl, Fig. 2(c)). The absolute difference in the arising anodic and cathodic potential, due to varied material combination, is about $\pm 300 \mathrm{mV}$ for both electrolytes.

\subsection{Friction tests}

The results of the friction tests are illustrated in Fig. 3. The tribotests were reproduced three times and showed a good reproducibility. The highest coefficient of friction (COF) was measured at cathodic polarization (1RK91/Al), whereas at nonpolarized state (1RK91/PTFE) the lowest COF was found for both electrolytes. In contrast to cathodic polarization there is a running-in behavior observable at anodic and nonpolarized condition within in the first $20 \mathrm{~min}$. The COF from the friction diagrams (Fig. 3(a),(b)) were integrated to calculate the friction work (Fig. 3(c), Table S4 in ESM). There is nearly no difference between the two electrolytes, but the material combination strongly influences the friction work. The combination 1RK91/ $\mathrm{Al}$ leads to the highest friction work, but there is also a slightly increase, when the combination 1RK91/Cu was tested. Consequently, compared to the non-polarized system at (1RK91/PTFE), cathodic polarization (1RK91/Al) resulted in a $45 \%$ increase of friction with $\mathrm{NaCl}$ and $36 \%$ with the ionic liquid. Anodic polarization $(1 \mathrm{RK} 91 / \mathrm{Cu})$ led to an increase of $15 \%$ and respectively $2 \%$.

\subsection{Wear analysis}

Figure 4 illustrates the wear volume of the 1RK91 disk and the $\mathrm{SiC}$ ball after friction test.
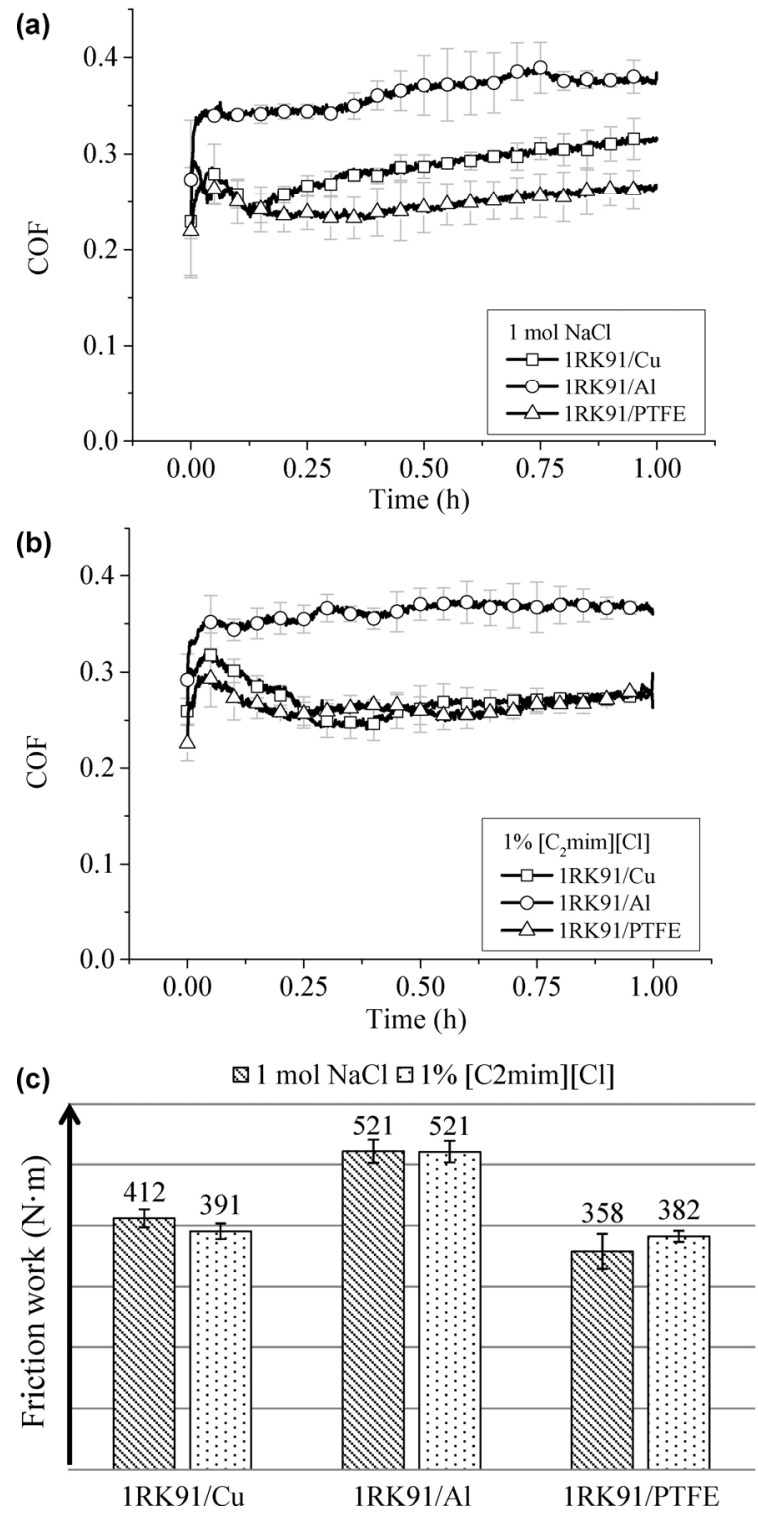

Fig. 3 Mean value of the coefficient of friction using different material combinations with 1 molar $\mathrm{NaCl}$ (a) and $1 \%\left[\mathrm{C}_{2} \mathrm{mim}\right][\mathrm{Cl}]$ (b) as electrolyte. (c) Overview of the mean value of the friction work using different material combinations with 1 molar $\mathrm{NaCl}$ and $1 \%\left[\mathrm{C}_{2} \mathrm{mim}\right][\mathrm{Cl}]$ as electrolyte.

Obviously, the polarization of the disk has a strong impact on the wear volume: At cathodic potential, when tribocorrosion processes are suppressed, the total wear volume of ball and disk is decreased by $86 \%$ in 1 molar $\mathrm{NaCl}$ and $74 \%$ in $1 \%\left[\mathrm{C}_{2} \mathrm{mim}\right][\mathrm{Cl}]$, in relation to the non-polarized system. In contrast, under anodic potential with accelerated corrosion conditions, severe wear occurs, at which the wear volume is increased by $69 \%$ in $\mathrm{NaCl}$ electrolyte and $23 \%$ in $\left[\mathrm{C}_{2} \mathrm{mim}\right][\mathrm{Cl}]$ solution compared to $1 \mathrm{RK} 91 / \mathrm{PTFE}$. 
In addition, the wear volume is also strongly affected by the electrolyte. Using $1 \%\left[\mathrm{C}_{2} \mathrm{mim}\right][\mathrm{Cl}]$ the wear volume was clearly reduced for the material combinations 1RK91/PTFE (48\%) and 1RK91/Cu (62\%), whereas no further decrease of wear volume was observed at cathodic polarization. The wear volume of ball and disk is nearly equal without polarization. In contrast, wear volume ratio of ball and disk decreases at cathodic polarization ( $\sim 0.4)$ and increases at anodic potential using 1\% IL (Fig. 4(c)). The values of the wear volume are listed in Table S5 in ESM and the images of wear track are illustrated in Fig. S4 in ESM (ball) and Fig. S5 in ESM (disk). Due to solid material contact during friction test wear grooves in sliding direction arise and therefore roughness increases for all combinations (Fig. S6) in ESM. Hence the friction and wear properties do not depend on a surface smoothing effect.
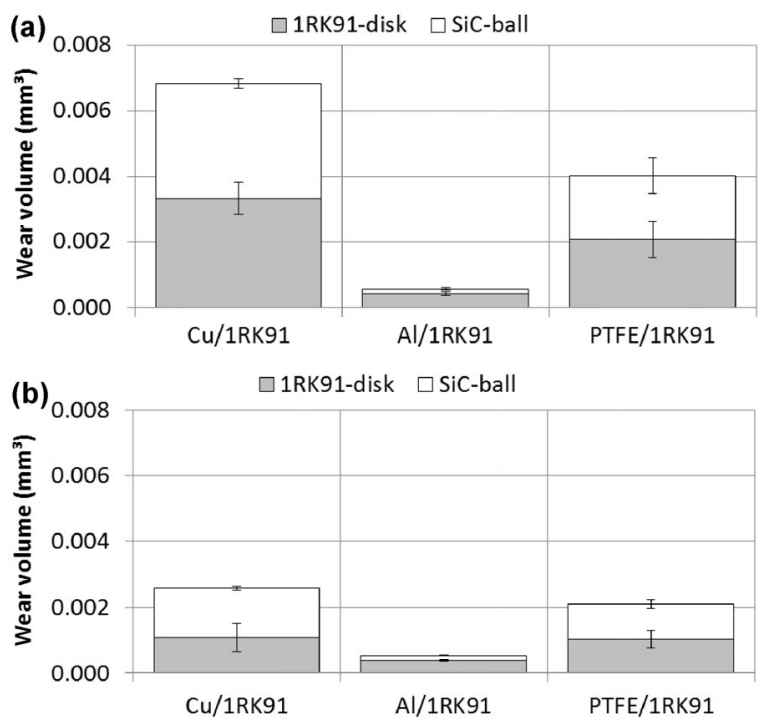

(c)

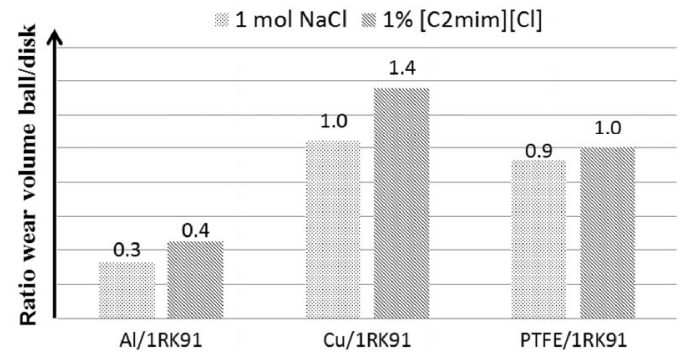

Fig. 4 Wear volumes of ball and disk after friction test with three different galvanic coupling elements (copper, aluminium and Polytetrafluoroethylene) in contact with steel 1RK91 disk using two different electrolytesafter tribotest $(10 \mathrm{~N}, 20 \mathrm{~Hz}, \mathrm{RT}, 1 \mathrm{~mm}$, $1 \mathrm{~h}$ ): (a) 1 molar $\mathrm{NaCl}$ solution; (b) $1 \%$ [ $\left.\mathrm{C}_{2} \mathrm{mim}\right][\mathrm{Cl}]$; (c) Ratio of wear volume of ball and disk.
Within the dynamic corrosion model published by Iwabuchi et al. $[58,59]$ the wear volume $W$ is composed of the mechanical wear $M_{0}$, static corrosion volume $C_{0}$ and the synergistic factor $\Delta W$, where $W_{\mathrm{d}}$ is called the dynamic corrosion factor:

$$
W=M_{0}+C_{0}+\Delta W=M_{0}+W_{\mathrm{d}}
$$

Due to sliding friction protective surface layer on the stainless steel gets destroyed and accelerated corrosion and wear mechanisms of fresh metal surface occur. Based on this model and the assumption that corrosive processes are completely suppressed it is possible to quantify the corrosive attack during these friction tests. Wear at friction tests without polarization (1RK91/PTFE) is composed according to Eq. (1) whereas wear after test at cathodic polarization (1RK91/Al) can be regarded as the pure mechanical wear. The dynamic corrosion factor generates from the difference in wear between these two testing conditions. As shown in Fig. 5(a) mechanical wear $\left(M_{0}\right)$ is the same using both solutions but the proportion of mechanical wear to the dynamic corrosion factor $\left(M_{0}: W_{d}\right)$ is much lower using 1\% IL (1:5) than $1 \mathrm{~mol} \mathrm{NaCl} \mathrm{(1:13).}$ This means that the dynamic corrosion can be strongly reduced using ionic liquid in contrast to sodium chloride. Regarding the amount of cathodic and anodic polarization based on the OCP of 1RK91 a correlation with total wear volume can be found (Fig. 5(b)).

In addition, wear analysis of the 1RK91 disks using scanning electron microscope were performed after tribotest (Fig. 6). The metallic surface and horizontal wear tracks in sliding direction are clearly visible after friction test at anodic polarization and no corrosion products are detectable. At nonpolarized condition there is little change on the surface visible after friction test and at cathodic polarization the worn surface appears quite different. It can be assumed that these changes are caused by tribochemical reactions.

\subsection{Investigation of tribolayer}

The worn surface was furthermore analyzed using Raman-spectroscopy to identify tribochemical reaction products. Oxides were identified based on literature data of different steel materials [60-63]. Steel 1RK91 shows Raman signals for $\mathrm{Cr}-\mathrm{O}\left(800 \mathrm{~cm}^{-1}\right)$, FeOOH 

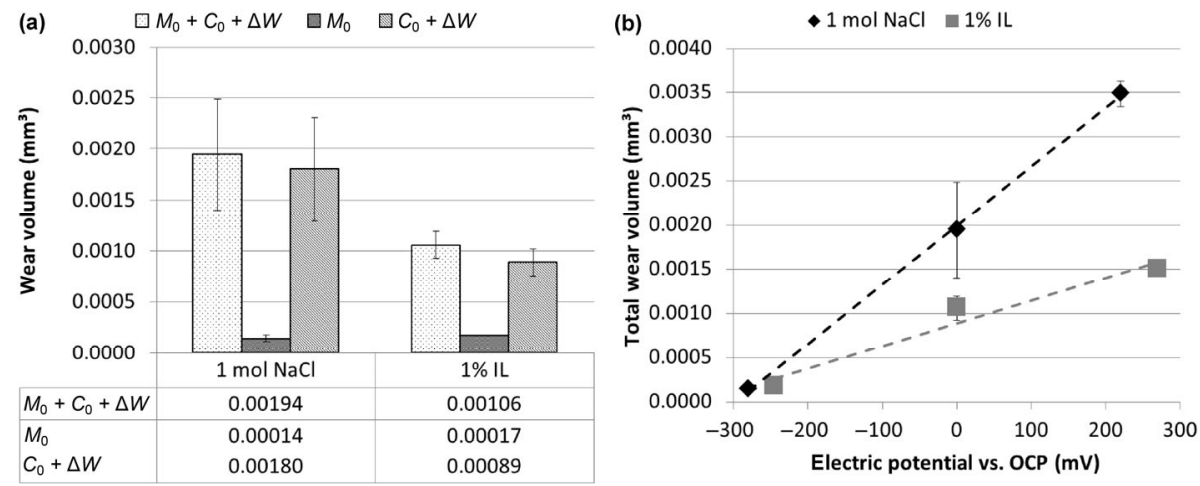

Fig. 5 (a) Determination of wear components based on dynamic corrosion model; (b) Correlation of total wear volume and galvanically induced electric potential.
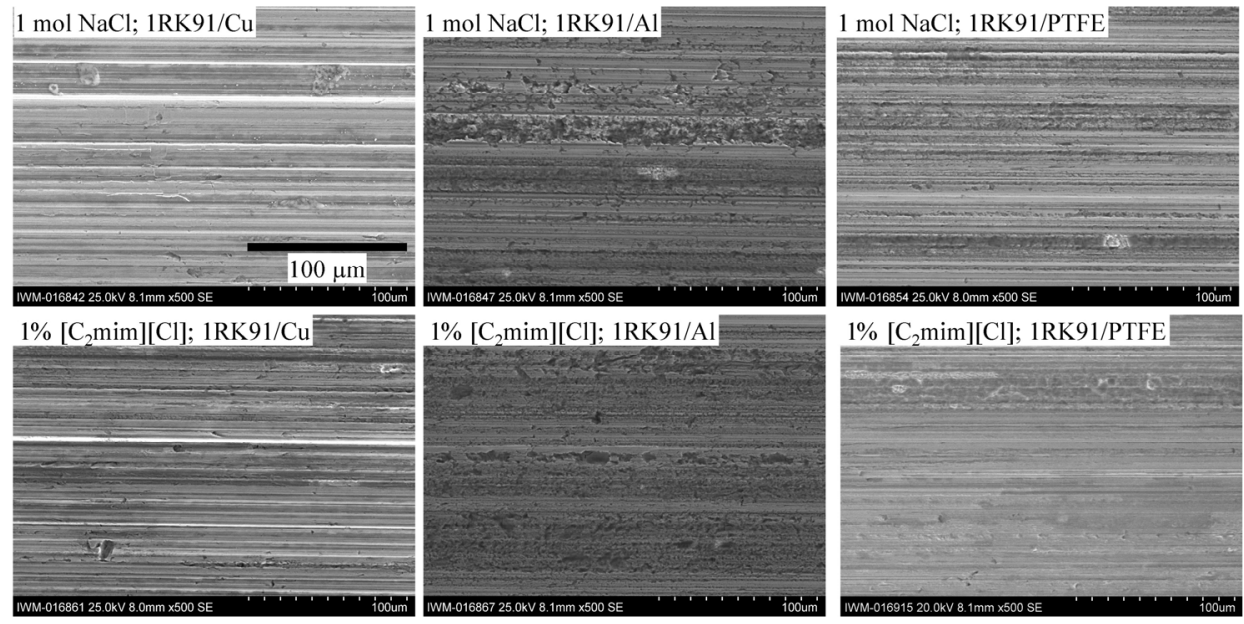

Fig. 6 Wear analysis of the 1RK91 disks using scanning-electron-microscope after tribotest (10 N, 20 Hz, RT, $1 \mathrm{~mm}, 1 \mathrm{~h})$ at different polarizations.

$\left(645 \mathrm{~cm}^{-1}\right)$ and $\mathrm{Cr}_{2} \mathrm{O}_{3}\left(540 \mathrm{~cm}^{-1}\right)$ in its unworn state. As listed in Table 1 and in accordance with the SEM images (Fig. 6) no further oxidation products were detected on the worn surface at anodic polarization. In contrast, without polarization more oxidation products are found on the wear track whereat cathodic polarization results in the strongest tribochemical changes as additional $\mathrm{Fe}_{2} \mathrm{O}_{3}$ is detected. The Raman spectra are given in Fig. S7 in ESM.

Using XPS-analysis the findings from Ramanspectroscopy were verified and, in addition, the thickness and chemical composition of the tribolayer was investigated. Therefore the atomic concentration of different elements and molecules were measured in relation to the sputter depth using $1 \%\left[\mathrm{C}_{2} \mathrm{mim}\right][\mathrm{Cl}]$ (Fig. 7). 1RK91 exhibits an oxide layer of $\approx 150 \mathrm{~nm}$. After friction test at cathodic polarization (1RK91/Al) a tribolayer of $\approx 800 \mathrm{~nm}$ was found consisting of carbon compounds $(\approx 25 \mathrm{~nm})$, chromium oxide $(\approx 500 \mathrm{~nm})$, and iron oxide $(\approx 800 \mathrm{~nm})$. At oppositional conditions with material combination $1 \mathrm{RK} 91 / \mathrm{Cu}$ the anodic potential leads to a formation of $\mathrm{a} \approx 350 \mathrm{~nm}$ thick tribolayer on the wear scar assembled of carbon compounds within the first $\approx 100 \mathrm{~nm}$ and chromium oxide till $\approx 350 \mathrm{~nm}$ without detection of iron oxide. Especially the content of chromium oxide and iron oxide strongly differs between anodic and cathodic conditions. Nearly the same thickness $(\approx 350 \mathrm{~nm})$ and chemical composition of the tribo-layer is detected without using an induced electrochemical potential (1RK91/PTFE). The only difference to anodic polarization is the higher amount of iron oxide in the tribo-layer at nonpolarized condition (Fig. 7(e)). Therefore it can be concluded, that in the case of cathodic polarization by aluminum, a 
Table 1 Raman signals $\left(\mathrm{cm}^{-1}\right)$ measured in the wear track of the 1RK91 disks after tribotest.

\begin{tabular}{|c|c|c|c|c|c|c|}
\hline \multirow{2}{*}{ Oxides } & \multicolumn{3}{|c|}{$1 \mathrm{~mol} \mathrm{NaCl}$} & \multicolumn{3}{|c|}{$1 \%\left[\mathrm{C}_{2} \mathrm{mim}\right][\mathrm{Cl}]$} \\
\hline & 1RK91/Cu & 1RK91/Al & 1RK91/PTFE & $1 \mathrm{RK} 91 / \mathrm{Cu}$ & 1RK91/Al & 1RK91/PTFE \\
\hline $\mathrm{Fe}_{2} \mathrm{O}_{3}$ & - & $490 ; 390 ; 280 ; 220$ & - & - & 500 & - \\
\hline $\mathrm{FeOOH} / \mathrm{Fe}_{3} \mathrm{O}_{4}$ & - & 1320 & 1350 & 1345 & 1330 & 1345 \\
\hline $\mathrm{FeOOH}$ & - & - & 725 & - & - & 740 \\
\hline $\mathrm{Cr}_{2} \mathrm{O}_{3}$ & - & 680 & 545 & - & 690 & 540 \\
\hline $\mathrm{Cr}-\mathrm{O}$ & 800 & - & $925 ; 875$ & 890 & - & - \\
\hline
\end{tabular}

(a)

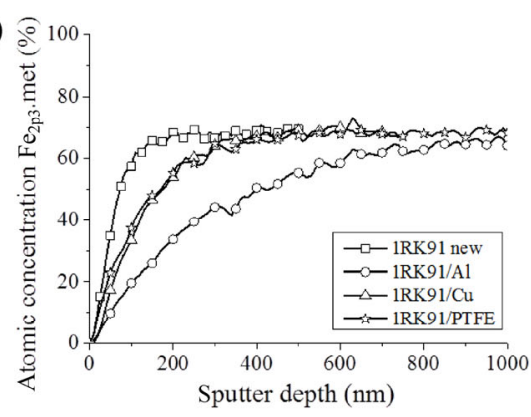

(b)
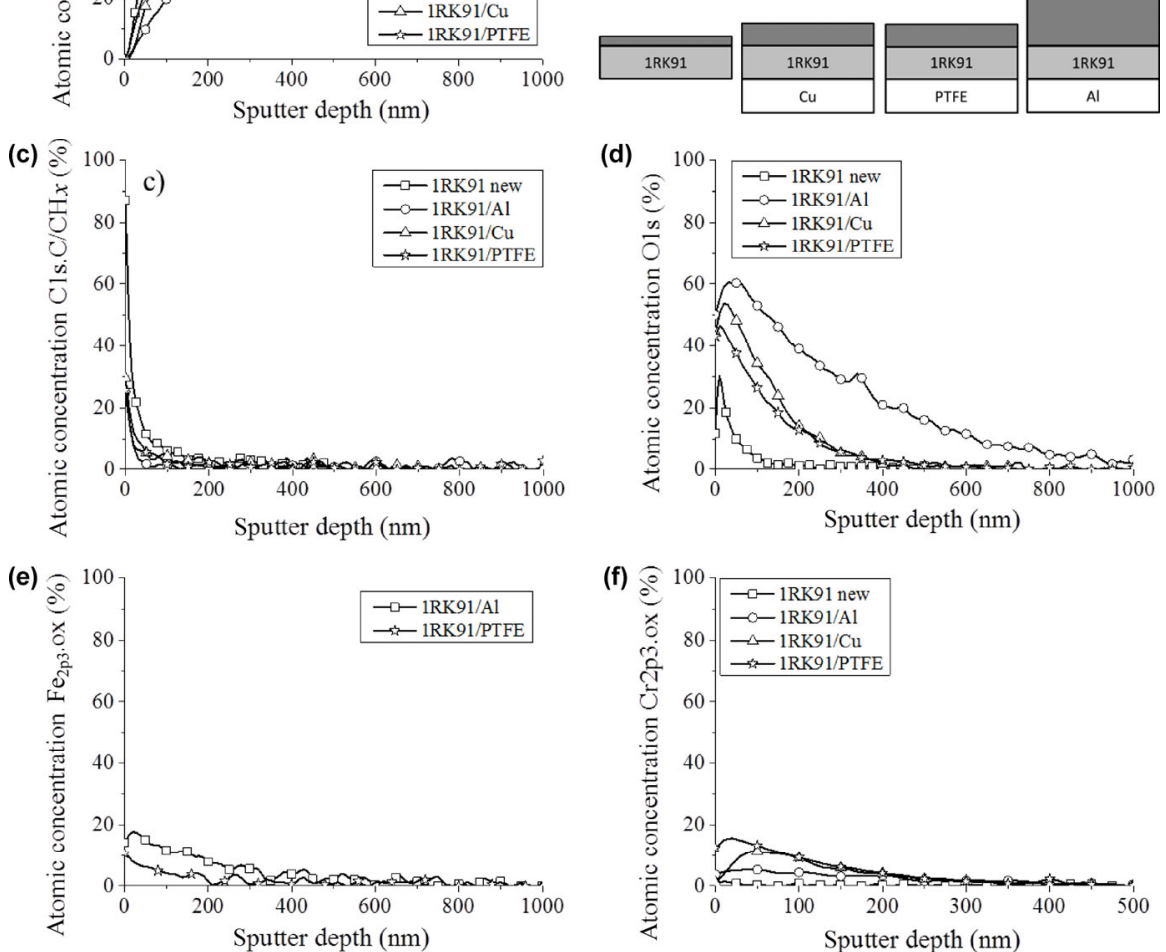

(d)
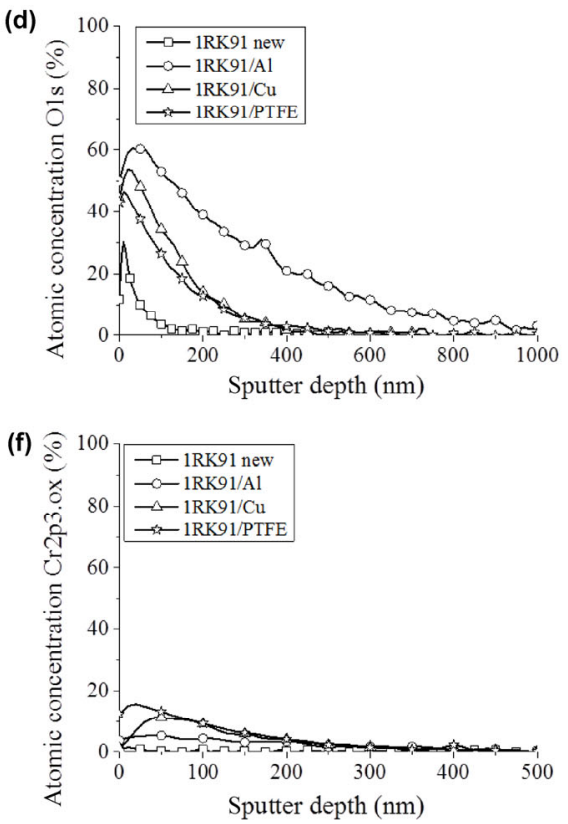

(g) $\square 1 \%[\mathrm{C} 2 \mathrm{mim}][\mathrm{Cl}]-\mathrm{Al} \backsim 1 \%[\mathrm{C} 2 \mathrm{mim}][\mathrm{Cl}]-\mathrm{Cu} \square 1 \mathrm{~mol} \mathrm{NaCl}-\mathrm{Al} \sim 1 \mathrm{~mol} \mathrm{NaCl}-\mathrm{Cu}$

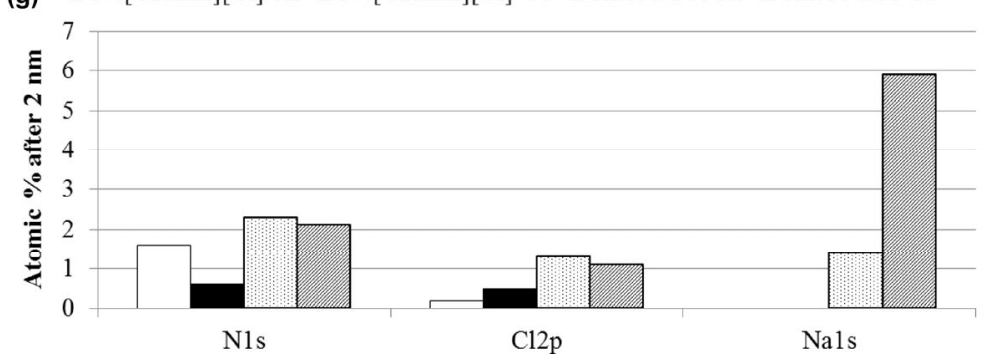

Fig. 7 XPS-analysis (sputter rate $\approx 10 \mathrm{~nm} / \mathrm{min}$ ) of new 1 RK91 material and wear scars on the disks after tribotest (10 N, $20 \mathrm{~Hz}, \mathrm{RT}$, $1 \mathrm{~mm}, 1 \mathrm{~h}$ ) using $\left[\mathrm{C}_{2} \mathrm{mim}\right][\mathrm{Cl}]$ with the different material combinations, e.g. polarizations: (a) metallic $\mathrm{Fe}_{2} \mathrm{p}_{3}$; (b) schematically illustration of tribo-layer thickness on 1RK91 after tribo-test; (c) $\mathrm{C} 1 \mathrm{~s} . \mathrm{C} / \mathrm{CH} x$; (d) O1s; (e) $\mathrm{Fe}_{2} \mathrm{p}_{3}$ oxide; (f) $\mathrm{Cr}_{2} \mathrm{p}_{3}$ oxide; (g) result of high resolution analysis of the first $2 \mathrm{~nm}$. 
stronger stabilization of the oxide layer predominates, whereby the formed oxide, which does not oxidize back, protects the surface more strongly from wear. Due to the way of galvanic coupling different tribochemical reactions occur during friction test on the anode and cathode. Combination of steel and copper causes an anodic polarization of the steel which is accompanied by high wear due to accelerated corrosion reactions. The generated oxides are permanently removed by friction so that no wear products were found on the wear track. The same tribochemical reactions arise in the nonpolarized state when coupling steel with PTFE with the difference that the corrosion isn't externally accelerated by an electrochemical potential. In this case only a small amount of oxidation products was found in the wear track (complete depth profiles including all elements are illustrated in Figs. S8 and S9 in ESM).

Additional XPS-measurements at high resolution constrain that both the cation and anion participated in the tribo-chemical thin film formation within the first $2 \mathrm{~nm}$ (Fig. 7(g)). The same result was found for the $1 \mathrm{~mol} \mathrm{NaCl}$ solution as $\mathrm{Na}$ and $\mathrm{Cl}$ was detected on the tribolayer.

In contrast, if 1RK91 is galvanically coupled with aluminum the steel surface should be electrochemically protected against corrosion. Surface analyses reveal that tribochemical reactions also occur on the wear track forming oxide layers, though the reaction kinetics are strongly retarded and therefore the wear volume is quite low. But it must be noticed that the corrosion resistance of the galvanically contacted lower aluminum disc is greatly reduced by aqueous salts, particularly in contact with dissimilar metals. This leads to pitting corrosion of the aluminum. The galvanically induced cathodic polarization of the steel surface results in electrochemical corrosion protection and the formation of a mechanically stable tribolayer.

\section{Conclusions}

The global challenge concerning friction and wear consists in the development of eco-friendly, sustainable and energy efficient lubricants. The problems by evolving such tribological systems, especially waterbased lubricants, are complex tribochemical reactions resulting in corrosion and accelerated wear. Moreover, pure water is inapplicable for tribological systems due to its low viscosity and high corrosivity. Application of external electrochemical potentials can be utilized to influence the corrosion behavior, tribochemical reactions, and adsorption of ions on the surface. The aim of this investigation was to explore and evaluate the electrochemical effects of metallic material combinations on tribocorrosive wear using galvanically induced potentials. Therefore we used a stainless steel material in metallic coupling with $\mathrm{Cu}$ and $\mathrm{Al}$ to induce different electrochemical potentials, which we tested in an oscillating friction mode in two different electrolytes. Galvanically induced cathodic potentials in tribological tests have proven to be a valuable method to significantly reduce wear in combination with water-based lubricants compared to the nonpolarized system. In conclusion, it was observed that the cathodic potential, which arises in an adapted galvanic cell, can be utilized to considerably reduce wear using 1 molar $\mathrm{NaCl}(86 \%)$ and $1 \%\left[\mathrm{C}_{2} \mathrm{mim}\right][\mathrm{Cl}]$ (74\%) electrolyte compared to the non-polarized system. In contrast, the galvanic coupling of stainless steel 1RK91 with the more noble copper results in an anodic polarization of the stainless steel leading to clearly enhanced wear. In addition, the electrolyte also affects the wear volume and the impact of galvanic potential: while $\mathrm{NaCl}$ solution leads to higher wear, at which mainly tribocorrosive mechanisms are relevant, the addition of an ionic liquid leads to potential-driven chemisorption effects that further reduce wear. It was found that mainly corrosive wear and not mechanical wear mechanisms are relevant in this tribological system. Therefore this technique is very promising to improve the tribological behavior of water-lubricated systems for technical applications. It is also noticeable that the galvanic potential is stable over the whole test duration. In contrast, friction work is increased for both polarizations compared to the non-polarized system, but isn't affected by the type of electrolyte. It is assumed that at negative potentials cations arrange into ion/ion pair layers with a high packaging density along the interface. XPS-measurements reveal that at cathodic polarization a thick tribolayer is formed and that both the cation and anion participated in the tribo-chemical thin film formation within the first $2 \mathrm{~nm}$. 


\section{Acknowledgement}

We gratefully acknowledge the he MFW-BW (MinisteriumfürWirtschaft, Arbeit und Wohnungsbau Baden-Württemberg, Project: BioSis) for funding this project. In addition, the authors thank Susanne Beyer-Faiß (Co. Dr. Tillwich GmbH Werner Stehr) and Dr. Maria Ahrens (Fa. Iolitec $\mathrm{GmbH}$ ) for fruitful discussions and Eberhard Nold for operating the XPS-measurements.

Electronic Supplementary Material: Supplementary material is available in the online version of this article at https://doi.org/ 10.1007/s40544-017-0198-y.

The surface characteristics and material compositions of the used materials are described in Figs. S1-S3 and Tables S1-S3. The corresponding wear values of Figs. 4-6 are listed in Tables S4 and S5. The wear patterns using laser scanning microscope are illustrated in Figs. S4 and S5. The resulting surface roughness on wear scar is shown in Fig. S6. The Raman spectra are given in Fig. S7. The complete profiles of XPS analysis of all detected elements on 1RK91 before and after tribological test are shown in Figs. S8 and S9.

Open Access: The articles published in this journal are distributed under the terms of the Creative Commons Attribution 4.0 International License (http://creativecommons.org/licenses/by/4.0/), which permits unrestricted use, distribution, and reproduction in any medium, provided you give appropriate credit to the original author(s) and the source, provide a link to the Creative Commons license, and indicate if changes were made.

\section{References}

[1] Persson B N J. Sliding Friction. Berlin, Heidelberg (Germany): Springer, 2000.

[2] Tzanakis I, Hadfield M, Thomas B, Noya SM, Henshaw I, Austen S. Future perspectives on sustainable tribology. Renew Sustain Energy Rev 16(6): 4126-4140 (2012)

[3] Holmberg K, Andersson P, Erdemir A. Global energy consumption due to friction in passenger cars. Tribol Int 47: 221-234 (2012)

[4] Mukhopadhyay A. Tribology: A potential source of energy savings in industry. Propag A J Sci Commun 2(2): 165-168 (2011)
[5] Nosonovsky M, Bhushan B. Green tribology: Principles, research areas and challenges. Philos Trans $R$ Soc London Ser A 368(1929): 4677-4694 (2010)

[6] Dong C L, Yuan C Q, Wang L, Liu W, Bai X Q, Yan X P. Tribological properties of water-lubricated rubber materials after modification by $\mathrm{MoS}_{2}$ nanoparticles. Sci Rep 6: 35023 (2016)

[7] Zeng Q F, Dong G N, Martin J M. Green superlubricity of Nitinol 60 alloy against steel in presence of castor oil. Sci Rep 6: 29992 (2016)

[8] Basumatary J, Nie M, Wood R J. The synergistic effects of cavitation erosion-corrosion in ship propeller materials. J Bio Tribo Corros 1(2): 12 (2015)

[9] Celis J P, Ponthiaux P, Wenger F. Tribo-corrosion of materials: Interplay between chemical, electrochemical, and mechanical reactivity of surfaces. Wear 261(9): 939-946 (2006)

[10] Gates R S, Hsu S M. Tribochemistry between water and $\mathrm{Si}_{3} \mathrm{~N}_{4}$ and $\mathrm{SiC}$ : Induction time analysis. Tribol Lett 17(3): 399-407 (2004)

[11] Somers A E, Howlett P C, MacFarlane D R, Forsyth M. A review of ionic liquid lubricants. Lubricants 1(1): 3-21 (2013)

[12] Palacio M, Bhushan B. A review of ionic liquids for green molecular lubrication in nanotechnology. Tribol Lett 40(2): 247-268 (2010)

[13] Ye C F, Liu W M, Chen Y X, Yu L Q. Room-temperature ionic liquids: A novel versatile lubricant. Chem Commun (21): 2244-2245 (2001)

[14] Qu J, Luo H M, Chi M F, Ma C, Blau P J, Dai S, Viola M B. Comparison of an oil-miscible ionic liquid and ZDDP as a lubricant anti-wear additive. Tribol Int 71: 88-97 (2014)

[15] Anand M, Hadfield M, Viesca J L, Thomas B, Battez A H, Austen S. Ionic liquids as tribological performance improving additive for in-service and used fully-formulated diesel engine lubricants. Wear 334-335: 67-74 (2015)

[16] Khemchandani B, Somers A, Howlett P, Jaiswal A K, Sayanna E, Forsyth M. A biocompatible ionic liquid as an antiwear additive for biodegradable lubricants. Tribol Int 77: 171-177 (2014)

[17] Qu J, Barnhill W C, Luo H M, Meyer III H M, Leonard D N, Landauer A K, Kheireddin B, Gao H, Papke B L, Dai S. Dai, S. Synergistic effects between phosphonium-alkylphosphate ionic liquids and zinc dialkyldithiophosphate (ZDDP) as lubricant additives. Adv Mater 27(32): 4767-4774 (2015)

[18] Somers A E, Khemchandani B, Howlett P C, Sun J Z, MacFarlane D R, Forsyth M. Ionic liquids as antiwear additives in base oils: Influence of structure on miscibility and antiwear performance for steel on aluminum. ACS Appl 
Mater Interfaces 5(22): 11544-11553 (2013)

[19] Kong L L, Huang W, Wang X L. Ionic liquid lubrication at electrified interfaces. J Phys D Appl Phys 49(22): 225301 (2016)

[20] Li H, Wood R J, Rutland M W, Atkin R. An ionic liquid lubricant enables superlubricity to be "switched on" in situ using an electrical potential. Chem Commun 50(33): 4368-4370 (2014)

[21] Ismail M, Harvey T, Wharton J, Wood R J K, Humphreys A. Surface potential effects on friction and abrasion of sliding contacts lubricated by aqueous solutions. Wear 267(11): 1978-1986 (2009)

[22] Kelsall G H, Zhu Y Y, Spikes H A. Electrochemical effects on friction between metal oxide surfaces in aqueous solutions. J Chem Soci Faraday Trans 89(2): 267-272 (1993)

[23] Brandon N P, Wood R J K. The influence of interfacial potential on friction and wear in an aqueous drilling mud. Wear 170(1): 33-38 (1993)

[24] Su Y Y, Marek M. Reduction of friction during wire drawing by electrode control. J Mater Eng Perform 4(2): 154-160 (1995)

[25] Chang Q Y, Meng Y G, Wen S Z. Influence of interfacial potential on the tribological behavior of brass/silicon dioxide rubbing couple. Appl Surf Sci 202(1-2): 120-125 (2002)

[26] Meng Y G, Hu B, Chang Q Y. Control of local friction of metal/ceramic contacts in aqueous solutions with an electrochemical method. Wear 260(3): 305-309 (2006)

[27] Chen Y J, Zuo Q Y, Huang P. Influence of electric double layers on elastohydrodynamic lubricating water film in line contact. Proc Inst Mech Eng Part N J Nanoengineering Nanosyst 227(4): 196-198 (2013)

[28] Bai S X, Huang P, Men Y G, Wen S Z. Modeling and analysis of interfacial electro-kinetic effects on thin film lubrication. Tribol Int 39(11): 1405-1412 (2006)

[29] Lantz M A, Wiesmann D, Gotsmann B. Dynamic superlubricity and the elimination of wear on the nanoscale. Nat Nanotechnol 4(9): 586-591 (2009)

[30] Li J J, Zhang C H, Cheng P, Chen X C, Wang W Q, Luo J B. AFM studies on liquid superlubricity between silica surfaces achieved with surfactant micelles. Langmuir 32(22): 55935599 (2016)

[31] Urbakh M, Meyer E. Nanotribology: The renaissance of friction. Nat Mater 9(1): 8-10 (2010)

[32] Rajauria S, Schreck E, Marchon B. Voltage assisted asymmetric nanoscale wear on ultra-smooth diamond like carbon thin films at high sliding speeds. Sci Rep 6: 25439 (2016)

[33] Alazizi A, Draskovics A, Ramirez G, Erdemir A, Kim S H. Tribochemistry of carbon films in oxygen and humid environments: Oxidative wear and galvanic corrosion.
Langmuir 32(8): 1996-2004 (2016)

[34] Watanabe S, Nakano M, Miyake K, Tsuboi R, Sasaki S. Effect of molecular orientation angle of imidazolium ring on frictional properties of imidazolium-based ionic liquid. Langmuir 30(27): 8078-8084 (2014)

[35] Khan S H, Kramkowski E L, Hoffmann P M. NaCl-dependent ordering and dynamic mechanical response in nanoconfined water. Langmuir 32(42): 10802-10807 (2016)

[36] Riley J K, Tilton R D. Sequential adsorption of nanoparticulate polymer brushes as a strategy to control adhesion and friction. Langmuir 32(44): 11440-11447 (2016)

[37] Phillips B S, Zabinski J S. Ionic liquid lubrication effects on ceramics in a water environment. Tribol Lett 17(3): 533-541 (2004)

[38] Omotowa B A, Phillips B S, Zabinski J S, Shreeve J M. Phosphazene-based ionic liquids: Synthesis, temperaturedependent viscosity, and effect as additives in water lubrication of silicon nitride ceramics. Inorg Chem 43(17): 5466-5471 (2004)

[39] Xie G X, Liu S H, Guo D, Wang Q, Luo J B. Investigation of the running-in process and friction coefficient under the lubrication of ionic liquid/water mixture. Appl Surf Sci 255(12): 6408-6414 (2009)

[40] Zhou Y, Qu J. Ionic liquids as lubricant additives: A review. ACS Appl Mater Interfaces 9(4): 3209-3222 (2017)

[41] Espinosa T, Jiménez M, Sanes J, Jiménez A E, Iglesias M, Bermúdez M D. Ultra-Low friction with a protic ionic liquid boundary film at the water-lubricated sapphire-stainless steel interface. Tribol Lett 53(1): 1-9 (2014)

[42] Gusain R, Gupta P, Saran S, Khatri O P. Halogen-free bis(imidazolium)/ Bis(ammonium)-Di[bis(salicylato)borate] ionic liquids as energy-efficient and environmentally friendly lubricant additives. ACS Appl Mater Interfaces 6(17): 15318-15328 (2014)

[43] Wasserscheid P, Welton T. Ionic Liquids in Synthesis. 2nd ed. Weinheim (Germany): Wiley-VCH, 2007.

[44] Li H, Wood R J, Endres F, Atkin R. Influence of alkyl chain length and anion species on ionic liquid structure at the graphite interface as a function of applied potential. $J$ Phys Condens Matter 26(28): 284115 (2014)

[45] Plechkova N V, Seddon K R. Ionic Liquids Uncoiled: Critical Expert Overviews. Hoboken, New Jersey (USA): John Wiley \& Sons, 2012.

[46] Seddon R K, Annegret S, Torres M J. Influence of chloride, water, and organic solvents on the physical properties of ionic liquids. Pure Appl Chem 72(12): 2275-2287 (2000)

[47] Astarita A, Curioni M, Squillace A, Zhou X, Bellucci F, Thompson G E, Beamish K A. Corrosion behaviour of stainless steel-titanium alloy linear friction welded joints: Galvanic coupling. Mater Corros 66(2): 111-117 (2015) 
[48] Dawson J L, Ferreira M G S. Crevice corrosion on 316 stainless steel in 3\% sodium chloride solution. Corros Sci 26(12): 1027-1040 (1986)

[49] Sato N. The stability of localized corrosion. Corros Sci 37(12): 1947-1967 (1995)

[50] Dold C, Amann T, Kailer A. Influence of electric potentials on friction of sliding contacts lubricated by an ionic liquid. Phys Chem Chem Phys 17(16): 10339-10342 (2015)

[51] Amann T, Dold C, Kailer A. Potential controlled tribological behavior of water-based ionic liquids. Key Eng Mater 674: 250-256 (2016)

[52] Amann T, Kailer A, Herrmann M. Influence of electrochemical potentials on the tribological behavior of silicon carbide and diamond-coated silicon carbide. J Bio Tribo Corros 1: 30 (2015)

[53] Kailer A, Amann T, Krummhauer O, Herrmann M, Sydow $\mathrm{U}$, Schneider M. Influence of electric potentials on the tribological behaviour of silicon carbide. Wear 271(9-10): 1922-1927 (2011)

[54] Amann T, Kailer A, Krummhauer O, Gumbsch P. Vorrichtung und verfahren zum betrieb eines tribologisch belasteten bauteils. German Patent 102010009507 (Sep. 2011).

[55] Landolt D, Mischler S. Tribocorrosion of Passive Metals and Coatings. New Delhi (India): Woodhead Publishing, 2011.

[56] Bidiville A, Favero M, Stadelmann P, Mischler S. Effect of surface chemistry on the mechanical response of metals in sliding tribocorrosion systems. Wear 263(1-6): 207-217 (2007)

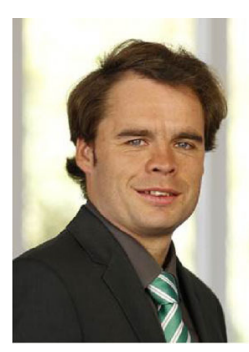

Tobias AMANN. He received his Ph.D. degree in chemistry from University of Freiburg, Germany, in 2013. Since then, he is postdoctoral researcher in the Tribology Depart-

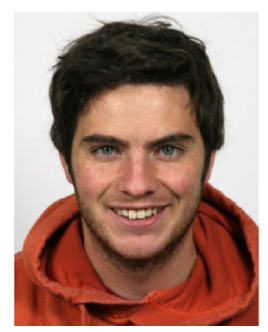

Felix GATTI. He received his bachelor and master degrees in chemistry in 2017 from University of Freiburg, Germany. Currently
[57] Vieira A C, Rocha L A, Papageorgiou N, Mischler S. Mechanical and electrochemical deterioration mechanisms in the tribocorrosion of $\mathrm{Al}$ alloys in $\mathrm{NaCl}$ and in $\mathrm{NaNO}_{3}$ solutions. Corros Sci 54: 26-35 (2012)

[58] Iwabuchi A, Sonoda T, Yashiro H, Shimizu T. Application of potential pulse method to the corrosion behavior of the fresh surface formed by scratching and sliding in corrosive wear. Wear 225-229: 181-189 (1999)

[59] Sato Y, Iwabuchi A, Uchidate M, Yashiro H. Dynamic corrosion properties of impact-fretting wear in hightemperature pure water. Wear 330-331: 182-192 (2015)

[60] Liu G, Xu Y L, Yang G X, Xiao X S, Chen X K, Zhang X K, Meng X J. Effects of alloy elements on oxidation resistance and stress-rupture property of P92 Steel. Acta Metall Sin Engl Lett 28(2): 129-138 (2015)

[61] Lu J F, Tsai C J. Hydrothermal phase transformation of hematite to magnetite. Nanoscale Res Lett 9(1): 230 (2014)

[62] Molchan I S, Thompson G E, Lindsay R, Skeldon P, Likodimos V, Romanos G E, Falaras P, Adamova G, Iliev B, Schubert T J S. Corrosion behaviour of mild steel in 1-alkyl-3-methylimidazolium tricyanomethanide ionic liquids for $\mathrm{CO}_{2}$ capture applications. RSC $A d v$ 4(11): 5300-5311 (2014)

[63] Otero-Lorenzo R, Weber M C, Thomas P A, Kreisel J, Salgueiriño $\mathrm{V}$. Interplay of chemical structure and magnetic order coupling at the interface between $\mathrm{Cr}_{2} \mathrm{O}_{3}$ and $\mathrm{Fe}_{3} \mathrm{O}_{4}$ in hybrid nanocomposites. Phys Chem Chem Phys 16(40): 22337-22342 (2014)

ment of Fraunhofer Institute for Mechanics of Materials IWM, where his current position is deputy group manager. His main research fields are lubricants (liquid crystals, ionic liquids), electrotribology, and tribocorrosion.

he is a Ph.D. student in the Tribology Department of Fraunhofer Institute for Mechanics of Materials IWM. His research interests include graphene, ionic liquids, and tribocorrosion. 


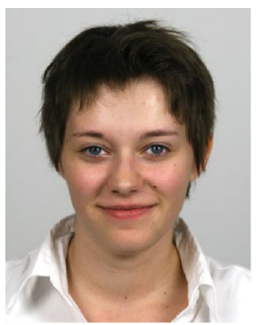

Natalie OBERLE. She received her bachelor degree in mechanical engineering in 2016 from Offenburg University of Applied Sciences, Germany. Currently she is working

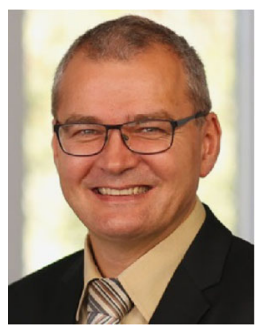

Andreas KAILER. He received his doctoral degree in applied mineralogy at University Tübingen, Germany in 1999 and then joined the Tribology Department of Fraunhofer

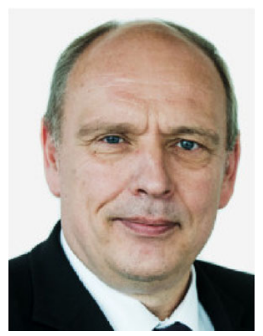

Jürgen RÜHE. He studied chemistry at the universities of Münster and Mainz. In 1989 he received his Ph.D. degree from the JohannesGutenberg University Mainz, Germany. Since 1999 he has a full on her master thesis in the Tribology Department of Fraunhofer Institute for Mechanics of Materials IWM. Her research focuses on the tribological behavior of ionic liquids and hydrogen embrittlement.

Institute for Mechanics of Materials, where his current position is group manager. His main research fields are tribology of ceramic materials, high temperature tribology, and tribocorrosion.

professor position as the chair for chemistry and physics of interfaces at the Department of Microsystems Engineering (IMTEK) at the University of Freiburg. His main research fields are surfaces, polymer chemistry, and polymer physics. 